DOI: $10.32481 / \mathrm{djph} .2021 .07 .003$

\title{
The Value (and Nuances) of Mapping as a Public Health Tool
}

\author{
James P. Highberger, MPA ${ }^{1}$ and Sharon Merriman-Nai, $\mathrm{MC}^{2}$ \\ 1. Research Associate, Center for Drug and Health Studies at the University of Delaware \\ 2. Senior Consultant, Center for Drug and Health Studies at the University of Delaware
}

\section{Introduction}

As technological barriers and cost of data entry have been reduced, the use of Geographic Information Systems (GIS) in public health will continue to increase. Scholars, public policy experts, and practitioners are all interested in place, space, and health. With Delaware's Open Data portal, FirstMap, and My Healthy Community dashboard, it is easier now than ever to access data and geocode it to produce heat maps that tell us important geographic stories regarding population health and well-being. Heat maps are data visualizations that use variation in color or shading to demonstrate how certain phenomenon change over geographic area. They can be used to explore the rate of health conditions in a region as well as social and environmental conditions that contribute to well-being including insurance coverage, educational attainment, poverty rates, the frequency of crime and acts of violence, etc. Because they can quickly convey a story, heat maps are popular for presentations and other data sharing strategies; feedback to the State Epidemiological Outcomes Workgroup from its network members suggest that they are among the most useful data products available. However, it is critical that GIS users and audiences take a moment to explore the scope and boundaries of the geographic unit of a given map to understand specifically what is being illustrated. Geographic units are predefined geographic areas, such as ZIP codes, census tracts, or census blocks that are used to break down larger areas such as towns, cities, counties, and states.

In this commentary, we consider how different geographic units can influence our understanding of important public health issues by comparing two poverty rate heat maps of New Castle County: the first based on census tracts and the second on ZIP codes. Poverty level was chosen because studies have consistently shown that economic and health status are intertwined with the stresses of poverty often being linked to adverse health effects. ${ }^{1}$ After highlighting the impact that a geographic unit can have on data visualization, we illustrate how heat maps designed by The Center for Drug and Health Studies (CDHS) at the University of Delaware have been used to track changes in substance use rates, identify resource desserts, and help policy makers and other stakeholders understand the health and prevention needs of various communities across the state.

\section{Exploring this Phenomenon with Delaware Data}

When creating public health maps, one of the first questions that researchers and practitioners must ask is what geographic unit they are going to use to capture and define an area of study, such as a neighborhood or community. The most common geographic unit to define neighborhoods in the social sciences is census tracts, ${ }^{2}$ because of the quantity of US Census data available. ${ }^{3}$ Other convenient units of analysis are ZIP codes because participants in studies will generally know their ZIP code and can provide this information. The use of these and other predefined geographic units is convenient, and allows users to access a wide range of information about these areas; they do have some limitations. 
When using mapping applications to tell the story of different neighborhoods, it is critical to know that there is no precise definition of "neighborhood" in either spatial extent or social composition. ${ }^{4}$ Rather, neighborhoods are context dependent, and do not fit neatly into predefined geographic units. ${ }^{3}$ Unlike census tracts and ZIP codes, neighborhoods are not isolated units; their borders are permeable and blend with one another. ${ }^{5}$ Studies have shown that when researchers and practitioners reject predefined geographic regions and instead use borders defined by neighborhood residents there may be noticeable impacts on social indicators ${ }^{5}$ that can result in a change of the statistics. ${ }^{2}$ Understanding the impact that selected geographic units have on data visualization helps to better inform policy, programs, and practices for members of the neighborhoods and communities who are the intended beneficiaries.

An example of the differences observed when we change the geographic unit of a heat map can be seen here in Delaware, especially in New Castle County, where characteristics of census tracts can vary greatly within small localities. Figure 1 provides a side-by-side comparison of the percentage of residents living in poverty in New Castle County by census tracts and by ZIP codes using data from the Delaware Opioid Metric Intelligence Project (DOMIP) (2017-IJ-CX0016), funded by the National Institute of Justice. ${ }^{6}$ Readers can see that though these two figures both identify areas in New Castle County that are below the federal poverty level, the shading between them varies a considerable amount.

Figure 1. Percent in Poverty in New Castle County; Shading Differences between Census Tracts and ZIP Codes ${ }^{6}$

Census Tract

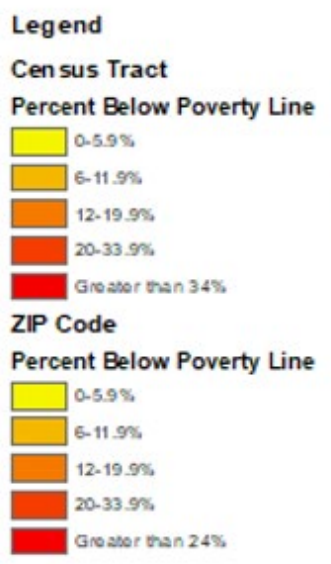

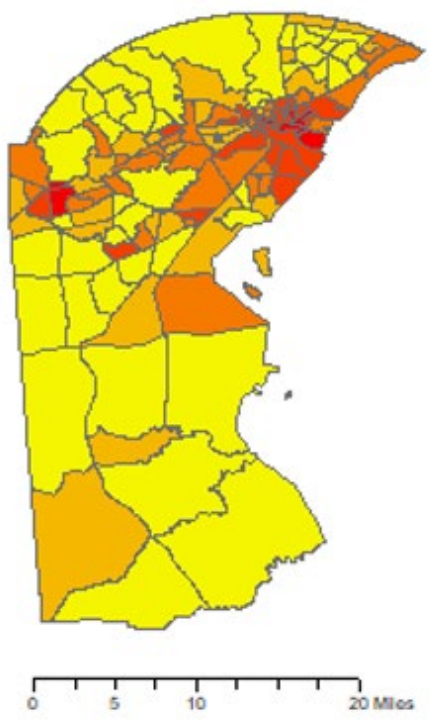

ZIP Code

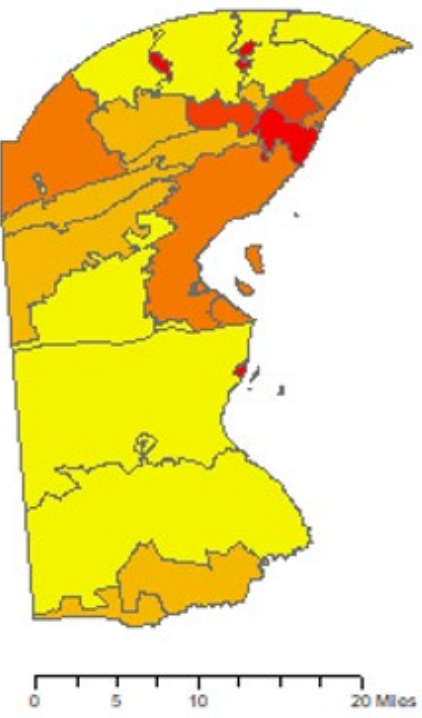

To further demonstrate the difference a geographic unit can have on visualization of data, Table 1 displays poverty rate and percentage of residents without health insurance between ZIP code 19711 and census tracts located within that ZIP code. Though ZIP code 19711 has an aggregated poverty rate of $16.53 \%$, the poverty rate for census tracts located within ZIP code 19711 ranges from $0.16 \%-64.52 \%$. Using summary statistics for the rates of poverty and percent of residents 
without health insurance, it is noticeable how even within a relatively small geographic unit such as a ZIP code, there is still a sizable amount of variance that can take place. This demonstrates that the summary characteristic of one geographic region maybe misleading and that pockets of demographic, social, and economic characteristics may not be captured in a specific geographic unit's summary statistic. ${ }^{3}$ Though these tables and figures demonstrate the relationship between ZIP codes and census tracts, other research has shown that this relationship is consistent when comparing smaller units, such as census tracts and census blocks. A census tract may have a summary statistic that reports the tract has a middle income, but the census tract may be composed of census blocks with high income and low income. ${ }^{2}$

Table 1. Poverty Rate and Percentage of Residents Without Health Insurance, ZIP Code $19711^{6}$

\begin{tabular}{|c|c|c|}
\hline ZIP Code & Poverty Rate & $\begin{array}{c}\text { Percent without Health } \\
\text { Insurance }\end{array}$ \\
\hline 19711 & $16.53 \%$ & $3.90 \%$ \\
\hline Census Tracts within 19711 & & \\
\hline 145.02-City Center & $64.52 \%$ & $2.20 \%$ \\
\hline 145.01 Nottingham Green & $63.69 \%$ & $5.77 \%$ \\
\hline 144.02- Fairfield Crest & $32.78 \%$ & $1.18 \%$ \\
\hline 143- Lumbrook & $12.44 \%$ & $2.24 \%$ \\
\hline 137-Eastburn Acres & $11.00 \%$ & $8.10 \%$ \\
\hline 136.11-Chapel Hill & $15.23 \%$ & $2.83 \%$ \\
\hline 136.10- Meadowood & $5.78 \%$ & $4.45 \%$ \\
\hline 135.06 North Star & $2.94 \%$ & $1.84 \%$ \\
\hline 135.05 Town Center & $0.16 \%$ & $2.49 \%$ \\
\hline
\end{tabular}

The above figure and table provide good insight into why users of heat maps must remember that there is often more to the story. These figures are able to showcase that the statistics, in this case poverty levels, can change when viewed using different geographic units. But they are also important reminders that though predefined geographic units such as ZIP codes and census tracts have clear borders, in reality neighborhoods blend together. When looking at the above figures, the borders for the ZIP code geographic unit does not align with the census tract borders. Instead, both units occupy different spaces, the clear distinction between the summary statistics of one unit and another are artificially created. This is necessary when creating maps using geographic regions, in order to manage and organize the data in a presentable manner. But it also indicates why policy and program developers must work at the ground level with local communities to understand a neighborhood's needs.

\section{Practical Applications: Using Heat Maps to Inform Delaware Health and Prevention Initiatives}

The Center for Drug and Health Studies (CDHS) at the University of Delaware is the home of a number of data collection and evaluation efforts, including the State Epidemiological Outcomes Workgroup (SEOW) and the Delaware School Survey (DSS). Both of these projects are funded with federal support through the Division of Substance Abuse and Mental Health, Delaware Department of Health and Social Services (DSAMH). The Center has produced a number of heat maps to support efforts for state agencies, nonprofit organizations, community groups, and researchers in the health and prevention fields. The SEOW, with the overarching mission to 
promote the use of data to support prevention and wellness, has presented these heat maps to stakeholders ranging from parenting groups to policy makers, and have included them in publications such as the annual Delaware Epidemiological Profile.

The Delaware School Survey (DSS) is an annual survey of $5^{\text {th }}, 8^{\text {th }}$, and $11^{\text {th }}$ grade public school students across the State of Delaware. The DSS provides estimates of students' attitudes towards and rates of alcohol, tobacco, and other drug use. The data is used for assessment, planning, and funding purposes and to provide ongoing trend data for state and local stakeholders, including individual districts and schools. A series of heat maps are drafted each year using DSS data. These heat maps track substance use across the state of Delaware for $8^{\text {th }}$ and $11^{\text {th }}$ graders, combining two years of data to ensure a large enough sample is pulled for robust analysis. The DSS also asks students to report their ZIP code which allows CDHS to create summary statistics for ZIP codes across the state for any question asked on the survey. The most common summary statistic produced is rate of reported substance use for each ZIP code, which is plugged into the mapping application, ArcGIS, to create a heat map of substance use across the state. An example of one of these maps can be seen in Figure 2.

Figure 2. Example of a Heat Map Created by the Center for Drug and Health Studies ${ }^{7}$ 


\section{Reported Past Month Vaping Device* \\ Use Among Delaware}

11th Grade Public School Students: 2018-2019
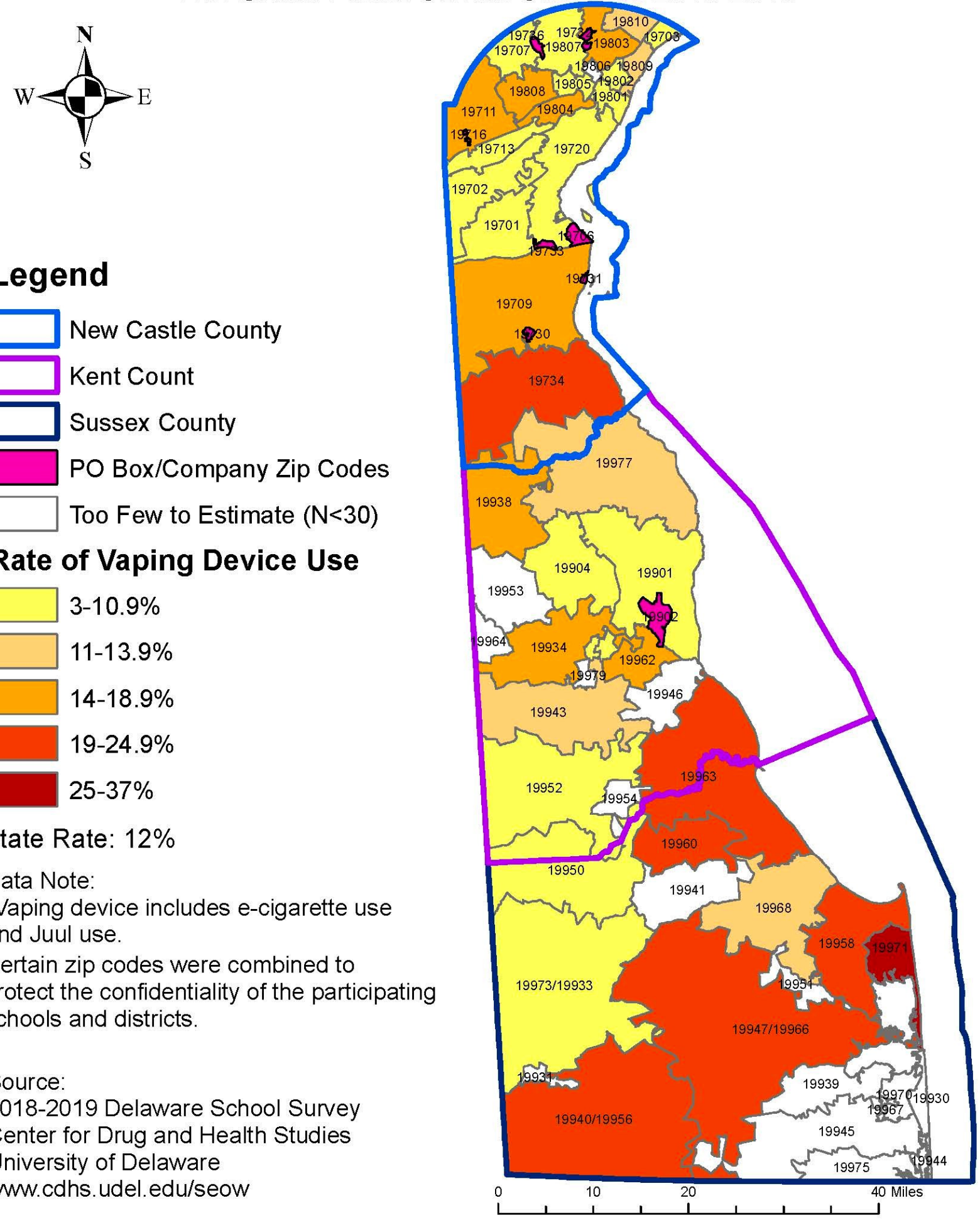

Legend

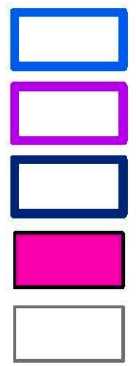

New Castle County

Kent Count

Sussex County

PO Box/Company Zip Codes

Too Few to Estimate $(\mathrm{N}<30)$

Rate of Vaping Device Use

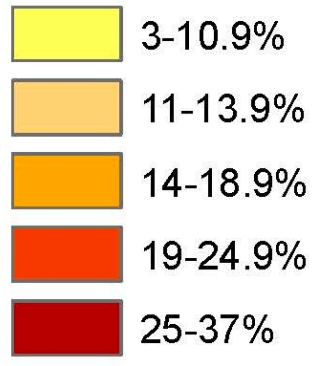

State Rate: $12 \%$

Data Note:

*Vaping device includes e-cigarette use and Juul use.

Certain zip codes were combined to protect the confidentiality of the participating schools and districts.

Source:

2018-2019 Delaware School Survey Center for Drug and Health Studies University of Delaware muw.cdhs. udel. edu/seow

\section{Practical Applications Using Delaware Data}


Heat maps are unique tools that can help practitioners, public policy experts, and community agencies better understand and respond to behaviors and conditions in their localities. For example, Delaware Alcohol and Tobacco Enforcement (DATE) was able to utilize the heat map depicting vaping and electronic cigarette use in Figure 2 to guide underage compliance checks. Other practitioners and prevention advocates involved with community organizations have used the Alcohol Use Map to guide their targeted efforts. Substance use heat maps have been included in grant proposals to document need and in progress reports to illustrate changes in conditions.

Heat maps that track a condition over time also illustrate rate changes, which is useful for trying to determine emerging trends or the effectiveness of programs and policies. With the series of Interactive Substance Use Maps developed by CDHS, users can track changes in specific consumption rates among $11^{\text {th }}$ graders from 2014 to 2019 throughout Delaware. For emerging trends such as vaping and electronic cigarette use, having data compiled in one location allows policy makers and practitioners to visualize the rapid increase in use.

Along with tracking changes in substance use or other behaviors of interest, GIS can also help plan resource allocation. Human resource deserts arise when residents do not have access to valuable health and social services without traveling far distances. Often times resource deserts are located in rural communities. Using GIS, policy makers are able to geolocate certain resources and identify areas that are lacking in specific services. This can help when trying to plan where to place valuable social service centers. Using GIS and in coordination with United Way of Delaware, CDHS was able to produce An After School Program Resource Map, which pinpoints available programs across the state and provides information about each program when users click on them. This resource map serves two functions: for parents or guardians it is an easy-to-use directory for locating accessible afterschool activities for their children. For policy makers and practitioners, the same map highlights the large areas without easy access to after school programming, thus guiding future initiatives.

The Delaware Opioid Metric Intelligence Project (DOMIP) is an example of an initiative that uses GIS to both track the rate of a public health issue and to provide information on available resources to address the issue. The interactive map series depicts overdose death rates from 2013 through 2019 by Zip code, census tracts, State House Districts, and county. It also maps substance use treatment resources including residential treatment, detox centers, methadone clinics, and transitional sober living services, along with other supportive services.

\section{Conclusion}

Whether tracking substance use rates, changes in behaviors and attitudes, or identifying resource deserts, GIS is a powerful tool that provides many benefits to a variety of audiences and users. However, it is paramount to understand both the strength and limits of GIS. To summarize, selection of geographic units can impact data visualization, how stories are told, and summary statistics of those regions. When using predefined geographic units there are clear boundaries between units such as census tracts and ZIP codes, but in reality, there are no clear boundaries between neighborhoods. Often time neighborhood boundaries and needs blend and merge with one another. When practitioners and policy experts rely solely on maps the result can be flawed findings and poor public policy decisions. ${ }^{2}$ This is especially problematic where there are pockets of missing data (for example, due to lack of participation) or when the geographic units of analysis are too large for meaningful interpretation (such as when only county or state level data are available). 
DOI: $10.32481 / \mathrm{djph} .2021 .07 .003$

As mapping tools and data become more accessible, there are many opportunities to apply them to identify emerging needs, resource deserts, and ideal program placements. They are particularly powerful in visualizing social determinants of health in association with rates of health conditions and behaviors. However, mapping also does not reflect the differences of how an individual or family may experience an adverse condition or their degrees of resilience which may be influenced by gender, race, culture, and other characteristics. GIS and other mapping tools are most effective when coupled with strong community engagement and input in order to maximize the benefit of this technology.

\section{Acknowledgement}

The authors would like to acknowledge and thank the Delaware Department of Health and Social Services, Division of Substance Abuse and Mental Health for funding the Delaware State Epidemiological Outcomes Workgroup (SEOW) and the Delaware School Survey (DSS), and the U.S. Department of Justice, National Institute of Justice, for funding the Delaware Opioid Metric Intelligence Project (DOMIP). We also wish to thank the team at the Center for Drug and Health Studies at the University of Delaware, including all survey administrators, for their diligence in data collection and analysis.

Correspondence

James P. Highberger, MPA is a Research Associate at the Center for Drug and Health Studies at the University of Delaware. iphigh@udel.edu

\section{References}

1. Wagstaff, A. (2002). Poverty and health sector inequalities. Bulletin of the World Health Organization, 80(2), 97-105. Retrieved from

https://www.ncbi.nlm.nih.gov/pmc/articles/PMC2567730/pdf/11953787.pdf Accessed April 26, 2021 PubMed

2. Sperling, J. (2012). The tyranny of Census geography: Small-area data and neighborhood statistics. Cityscape (Washington, D.C.), 14(2), 219-223. Retrieved from http://www.jstor.org/stable/41581107 Accessed April 26, 2021

3. Coulton, C. J., Korbin, J., Chan, T., \& Su, M. (2001, April). Mapping residents' perceptions of neighborhood boundaries: A methodological note. American Journal of Community Psychology, 29(2), 371-383. Accessed April 26, 2021. https://doi.org/10.1023/A:1010303419034 PubMed

4. Knaap, E., Wolf, L. J., Rey, S. J., Kang, W., \& Han, S. (2019, February 27). The dynamics of urban neighborhoods: a survey of approaches for modeling socio-spatial structure. Retrieved April 26, 2021 from https://doi.org/10.31235/osf.io/3frcz

5. Morenoff, J. D., Sampson, R., \& Raudenbush, S. (2001). Neighborhood Inequality, collective efficacy, and the spatial dynamics of urban violence. Criminology, 39, 517-558. Retrieved from https://scholar.harvard.edu/files/sampson/files/2001_crim.pdf Accessed April 26, 2021 https://doi.org/10.1111/j.1745-9125.2001.tb00932.x 
6. Anderson, T. L. (Principal Investigator) and O’Connell, D. (Co-Investigator). "Delaware Opioid Metric Intelligence Project," (2017-IJ-CX-0016), funded by the National Institute of Justice, US Department of Justice. https://www.cdhs.udel.edu/projects/domip

7. University of Delaware Center for Drug and Health Studies. (n.d.). The State Epidemiological Outcomes Workgroup. Retrieved from: https://www.cdhs.udel.edu/seow/what-is-seow

Copyright (c) 2021 Delaware Academy of Medicine / Delaware Public Health Association.

This is an Open Access article distributed under the terms of the Creative Commons Attribution Non-Commercial License (https://creativecommons.org/licenses/by-nc-nd/4.0/) which permits unrestricted non-commercial use, distribution, and reproduction in any medium, provided the original work is properly cited. 